\title{
An investigation of Open University Students' Silence in English Class
}

\author{
Tang Qi, Zhou Shu \\ Si Chuan Open University
}

\begin{abstract}
Teachers-centeredness is a serious problem in the present English teaching and learning in Open University and it should be paid attention. This phenomenon means in the English class students learn English very passively. It is obvious that students who don't take part in the class actively show silence in Open English teaching, which is not good for students'learning of English. Therefore, it is urgent to deal with the phenomenon of students' silence in Open English class. Based on this background, this investigation aims to investigate the students' silence and explore the reasons lead to silence and then put up some effective measures to reduce classroom silence in Open University. In this investigation, questionnaire and class observation are used to investigate one hundred and forty students in Nan Chong Open University. The author proposed two questions in the process of investigation based on the research purpose. Finally, the research questions are answered and some proper measures are provided.
\end{abstract}

Key words: silence; Open English; class; Open University

\section{INTRODUCTION}

Interaction and communication between students and teachers are regarded as an effective way of English language learning. Meanwhile, silence in classroom is usually considered to be a passive effect on language learning. Silence, on the other hand, is regarded as a negative behavior which is considered to be a common phenomenon among vocational students, especially the Open University students. The Open University is a new kind of higher education institution that offers open and distance education using modern information technology. It is directly administered by China's Ministry of Education, and is dedicated to both degree and non-degree further education. The unwillingness of thinking, speaking and answering questions in class give fewer opportunities to promote their English. The activity in the class is actually end because of the silence from students. Therefore, it is necessary for teachers to understand the reasons why Open University students keep silence in class. When teachers know the factors they will take some proper measures to deal with such a phenomenon in language class.

English as a foreign language teaching in China has seen a shift from the concept of teacher-centered ness to the concept of learner-centeredness, in which the learning of language through active interaction with teachers and students is encouraged.

With the Open University students as the main participants in the study, this research aims to find out to what extent students the students are keeping silence in class, and what are the reasons for students to keep silence? Through identifying the questions, some effective measures are taken to reduce students' silence in class. To achieve the goal, some carefully planned measures are used the study. The ultimate aim of Open English Language Teaching is to enable students to effective communication with others in society.

\section{LITERATURE REVIEW}

\subsection{Definition of Silence}

As a complex, multidimensional phenomenon, silence has been proved to exist in second/foreign language classrooms and predominantly act as a debilitator (Liu, 2006; Liu and Littlewoods, 1997; Tsui, 1996; Zou, 2004). Most researches interpreted silence as face saving, a difficulty voidance strategy, or a silent request for help which is acceptable, tolerable, $\mathrm{r}$ indeed productive if teachers are able to engage with students' non-verbal responses. However, most British informants interpreted silence negatively as a sign of no interest, boredom, or laziness. In effect, "there are as many kinds of silence as there are of 
relevant sounds" (Bilmes, 1994, p. 79). However, for the purpose of this paper, silence is defined as a pause in the dialogue or a teaching activity during the class time where the student is speaking in the present study.

\subsection{Researches of Classroom Silence Abroad and at Home}

Research on the issue of silence in the classroom context focuses mostly on the experiences of students from Asia with Western teachers or in Western educational systems. One view to interpret silence in classrooms is a culturalist approach which points out the culturally different understandings of silence (Hu \& Fell-Eisenkraft, 2003). Another perspective suggests that silence is an outcome of interactions between students and/or teachers in North American classrooms (Lee, 1996; Losey, 1997; Pon et al., 2005). Hu \& Fell-Eisenkraft (2003) focus on immigrant Chinese eighth graders in New York City. This study analyzes silence in a classroom from two standpoints; that of a cultural insider $(\mathrm{Hu})$ and a classroom insider (Fell-Eisenkraft). They break silence down to four themes, "silence as a result of being shy," "silence as a result of not having the correct answers," "silence as a result of unfamiliarity with talking to learn," and "silence as a result of a lack of confidence in speaking the English language." Studies of language classroom silence are carried out later than the studies abroad In fact, for such a long time, English language teaching has been paid more listening are regarded as little help because of the traditional evaluation system of language teaching and learning in china. Many researchers such as Wu Zhonghua (2008) stated that Chinese learners are more likely to keep silent in the language class and writing and remembering what they have learned rather than express themselves' thoughts freely. Li Jing guang (2010) uses emotion-filter theory to explain the classroom silence phenomenon, and some reasons of classroom silence are put up, such as, traditional teaching concepts, Chinese traditional culture, and teaching methods, teacher's factors as well as students' factors. Du Jianjun (2011)finds out the reasons resulted in classroom silence are mainly form two aspects: teachers' factors and students' factors, such as, lack of confidence, low interest, students' low proficiency and the effect of traditional culture, teacher's evaluation methods and teaching methods. Zhang Juanjuan (2011) argues that vocational students' silence is very common in English classroom, most of the vocational English learners keep silent in the classroom.

\section{ANaLysis of SilenCe Degree in Class}

Considering the degree of Open University students' silence in English class, the author made observations of the three classes during the four weeks. The data showed the performance by students in English classes and the specific results are provided in the following tables.

According to the observation, the data can show in table 3:

Table3.1. The ratio of questions answered by students

\begin{tabular}{|l|c|c|c|}
\hline Questions types & Number of type & $\begin{array}{l}\text { Number of questions answered } \\
\text { by students }\end{array}$ & Ratio of answered questions \\
\hline Open-ended questions & 42 & 26 & 52.47 \\
\hline Closed questions & 202 & 150 & $74.53 \%$ \\
\hline Total & 244 & 176 & \\
\hline
\end{tabular}

In the observation, the teacher record the questions the teachers asked in the three classes. All questions can be divided into closed questions and open-ended questions. During the period of observation, the teacher asked 202 closed questions such as Do you think the statement is true and 42 questions like could you please summarize the general idea of this paragraph? Only 52.47\% of the open-ended questions were answered which reveals that the students prefer closed questions and they would rather keep silent in the class.

Evidence of the students' silence in class can also get from the number of students who are interested in taking part in the teacher actively. The classroom climate and the enthusiasm of the students also showed great influence on the frequency of answered questions. Data in following three tables can illuminate the influence of classroom environment on students' positivity in taking part in the activities.

Table3.2. Class One

\begin{tabular}{|l|c|c|c|}
\hline & Students that answer questions & Total number of the students & Ratio \\
\hline The most active class & 7 & 53 & $13.21 \%$ \\
\hline The least active class & 3 & 53 & $5.66 \%$ \\
\hline
\end{tabular}


Table3.3. Class Two

\begin{tabular}{|l|l|c|l|}
\hline & Students that answer questions & Total number of the students & Ratio \\
\hline The most active class & 10 & 45 & $22.17 \%$ \\
\hline The least active class & 3 & 45 & $6.66 \%$ \\
\hline
\end{tabular}

Table3.4. Class Three

\begin{tabular}{|l|c|c|c|}
\hline & Students that answer questions & Total number of the students & Ratio \\
\hline The most active class & 14 & 42 & $33.24 \%$ \\
\hline The least active class & 2 & 42 & $4.76 \%$ \\
\hline
\end{tabular}

As revealed in above tables, in most active class, the students that contributed to classroom activities takes up $13.21 \%, 22.17 \%$ and $33.24 \%$ in three classes respectively. While in the least active atmosphere, the percent of students touched the bottom of $5.66 \%$, which presents that most students refused to air their views regardless of whether they have an answer. In the observation, the author also found that some students who are interested in English while quite a few students did not answer a question at all. A conclusion can be safely drawn that the degree of students' silence in English classroom varies among Open University students and most students fail to take part in the activities.

\section{Analysis of Students' Individual FaCtors of ClassRoom Silence}

\subsection{Language Learning Attitude}

In the class, when the teacher asks questions, in most instances, there is no volunteer to answer them. Most students keep silent except they are asked to answer the questions. We can see Open University students' attitude toward learning English.

Table4.1. Their views on spoken English

\begin{tabular}{|l|l|l|l|l|l|}
\hline \multicolumn{1}{|l|}{ Statements } & \multicolumn{3}{l|}{ Strongly agree---- strongly disagree (\%) } \\
\hline 2. English learning focuses on oral language & 44.98 & 35.44 & 12.43 & 7.07 & 2.08 \\
\hline $\begin{array}{l}\text { 11. Communicative competence is very important, so the } \\
\text { speaking class is necessary }\end{array}$ & 40.34 & 38.38 & 11.43 & 7.49 & 2.36 \\
\hline 12. I like the sound of English & 20.76 & 35.62 & 25.44 & 17.22 & 0.96 \\
\hline 15. I often participate in classroom activities actively. & 11.38 & 40.45 & 29.81 & 17.09 & 0.97 \\
\hline 16. I ask when I have a question in hand & 6.88 & 21.78 & 35.67 & 31.47 & 4.20 \\
\hline 17. eagerness to answer questions & 2.63 & 20.71 & 35.67 & 38.89 & 2.10 \\
\hline 18. Ask when have different opinion with the teacher & 4.82 & 21.84 & 34.54 & 35.68 & 3.17 \\
\hline 19.Put up different opinion with the students immediately & 12.22 & 30.35 & 36.67 & 19.99 & 1.02 \\
\hline 21.seldom to answer the questions voluntarily & 12.22 & 38.80 & 25.03 & 21.79 & 2.12 \\
\hline 22.Kepp silent in English class & 10.14 & 28.22 & 29.88 & 24.44 & 7.32 \\
\hline $\begin{array}{l}\text { 25.Communicating in activities does not affect the score in } \\
\text { the examination, so I would rather keep silent }\end{array}$ & 0.99 & 15.54 & 28.64 & 45.24 & 8.58 \\
\hline 26English is useless to me & 6.19 & 12.97 & 8.91 & 45.34 & 26.80 \\
\hline 35.Always being passive and being accustomed to it & 7.44 & 35.67 & 22.84 & 27.64 & 6.62 \\
\hline
\end{tabular}

From the data in the table, it is known that as many as $75.38 \%$ of the investigated students agreed that oral language is a very important part in English learning, $68.57 \%$ of the students thought communicative competence is very important, and $55.26 \%$ of the students liked the sound of English. Most students held the point that spoken English is necessary and of great importance. The data of students' behavior in English classroom, 51.83\% of the students held the point that they participate in classroom activities actively and $28.66 \%$ of the students asked the teacher immediately when they had a question, and only $23.34 \%$ showed the eagerness to answer questions. In the classroom, there were some students participating in activities actively, but few students answered the questions voluntarily, which just suggested students' low eagerness. Statement 18 and statement 19 revealed students' behaviors when they had different views with the teacher or other students, $27.64 \%$ and $43.11 \%$ of the students would present their own opinions when they had different views with the teacher and other classmates respectively. $50.86 \%$ of the students agreed that they seldom answered questions voluntarily and $38.89 \%$ thought they kept silent in English class.

In the reasons of their behaviors, $16.53 \%$ of the students agreed that communicating did not affect their scores in the examination. This reflects the influence of outdated teaching method, $43.01 \%$ believed they had accustomed to being passive in English class 19.06\% even though English is useless. 


\subsection{Low English Proficiency}

The data from questionnaires show the influence of this factor upon the performance of Open University students in English classes. The data showed that $52.86 \%$ of the students regarded low English proficiency as the problem that bothering them and prevented them from expressing their opinions. So this factor was a barrier for many students in aspect of playing a part in the interaction in English classroom activities. In conclusion, low English proficiency was thought by most students as a reason why they kept silent in the class

Table4.2. Statement 27: low proficiency of English inhibits me expressing ideas

\begin{tabular}{|l|c|c|}
\hline 5-point & Frequency $(\mathrm{n}=140)$ & Valid percent (\%) \\
\hline Valid & & \\
1.strongly agree & 25 & $17.86 \%$ \\
2.agree & 49 & $35 \%$ \\
3.uncertain & 35 & $25 \%$ \\
4.disagree & 19 & $13.6 \%$ \\
5.strongly disagree & 12 & $0.54 \%$ \\
\multicolumn{1}{|c|}{ Total } & 140 & 100.0 \\
\hline
\end{tabular}

\subsection{Affective Factors}

Learning anxiety and lack of confidence are affective factors that prevent students from airing their opinions freely. As high as $42.14 \%$ of the total number thought they were afraid of making mistakes, so they did not want to participate in the interaction that most likely to improve their English competence and just kept silent.

Table4.3. Statement 20: being afraid of making mistakes

\begin{tabular}{|c|c|c|}
\hline 5-point & Frequency $(n=140)$ & Valid percent (\%) \\
\hline Valid & & \\
\hline 1.strongly agree & 15 & $10.71 \%$ \\
\hline 2.agree & 44 & $31.43 \%$ \\
\hline 3.uncertain & 34 & $24.28 \%$ \\
\hline 4.disagree & 34 & $24.28 \%$ \\
\hline 5.strongly disagree & 13 & $9.30 \%$ \\
\hline Total & 140 & 100.0 \\
\hline
\end{tabular}

Interest is regarded as the best teacher of learning. It is obvious that a person can not learn something very well when he/she has no interest in it. Statement 23 and 24 are about students' interest in English learning.

The data presented that $50.87 \%$ of the students were interested in what the teacher taught, while $36.22 \%$ did agree that teaching content could not attract their attention. As about a half of the students felt they were not interested in what they were teaming, it was no wonder that many students played passive roles in interactions.

Table4.4

\begin{tabular}{|l|l|l|l|l|l|}
\hline Statements & \multicolumn{3}{|l|}{ Strongly agree--- strongly disagree (\%) } \\
\hline I like English and am interested in what the teacher teaches & 18.04 & 32.83 & 24.97 & 18.89 & 5.38 \\
\hline I have no interest what the teacher teaches & 6.74 & 23.35 & 24.09 & 27.77 & 8.45 \\
\hline
\end{tabular}

Motivation is considered as a factor that affects students' performance in the class. This table can reflect students' motivation of learning English. 70.3\% of the Open University students held the point that they learned English in order to find a better job in the future, this is instrumental motivation; $73.25 \%$ thought learning English could enable them to know about other culture and see and understand the world in a different way. This is integrated motivation. The integrated motivation was shown a little higher share than instrumental motivation among Open University students in learning English.

Table4.5

\begin{tabular}{|l|l|l|l|l|l|}
\hline Statements & \multicolumn{3}{|l|}{ Strongly agree--- strongly disagree (\%) } \\
\hline 13. Learning English in order to find a better job in the future. & 18.19 & 51.11 & 13.78 & 13.78 & 3.14 \\
\hline $\begin{array}{l}\text { 14. Learning English enables me to get to know other culture, } \\
\text { and see and understand the world in a different way. }\end{array}$ & 30.70 & 42.55 & 18.14 & 4.13 & 4.13 \\
\hline
\end{tabular}




\subsection{Cultural Influence}

Influenced by Chinese culture, face is important to all the people including the students. Many students keep silent in English classroom activities in order to keep their face; they think that if they answer a question incorrectly they will lose face. They do not want to do "face threatening acts". They see keeping silent as a means to keep face in English class activities. The result of the questionnaires which reveals Open University students' opinions is shown in the following table.

Table4.6

\begin{tabular}{|l|l|l|l|l|l|}
\hline Statements & \multicolumn{4}{|l|}{ Strongly agree---- strongly disagree (\%) } \\
\hline 33. Being afraid of making mistakes and losing face. & 4.11 & 14.84 & 31.96 & 37.16 & 11.72 \\
\hline 34. Being afraid of being too pushy. & 5.15 & 14.84 & 24.52 & 40.39 & 14.90 \\
\hline
\end{tabular}

Though many people think that they have their unique ideas and dare to show their intelligence in public, cultural factor shows its impact on Open University students. $18.95 \%$ of the students agreed that they were afraid of making mistakes and losing face, and $20.19 \%$ were afraid of being too pushy and misunderstood by their classmates; nearly one third of the students had no idea about this. It is obvious that the cultural factor is deep-rooted in the students and it influences the students psychologically.

\subsection{Personality}

In this research, in the questionnaire only one statement about personality and the result is shown in the table. There were $59(n=140)$ of the Open University students thought they are introverted person and their character prevented them from answering questions and participating in classroom interaction. This demonstrates that many extroverted students do not want to take the risk of answering questions; classroom silence is not only the fault of introversion.

We can see students with introverted personality always keep silent; students with combined characters can participate in classroom activities; students with extroverted personality can perform differently. One can participate in classroom activities actively and the other would rather keep silent. The data above present personality has some relationship with their classroom performance to some extent.

Table4.7

\begin{tabular}{|c|c|c|}
\hline 5-point & Frequency $(n=140)$ & Valid percent (\%) \\
\hline Valid & & \\
\hline 1.strongly agree & 15 & $10.71 \%$ \\
\hline 2.agree & 44 & $31.43 \%$ \\
\hline 3.uncertain & 34 & $24.28 \%$ \\
\hline 4.disagree & 34 & $24.28 \%$ \\
\hline 5.strongly disagree & 13 & $9.30 \%$ \\
\hline Total & 140 & 100.0 \\
\hline
\end{tabular}

\section{Analysis of Teacher's Factors of Classroom Silence}

\subsection{Traditional Teaching Method}

In the questionnaires, the following three statements try to examine the influence of traditional teaching method: As was revealed in the table, $37.20 \%$ of the students agreed that the teacher spent a lot of time organizing activities for the students to practice oral English, the other students did not sure or disagreed; $72.20 \%$ of the students thought the materials they used contained lots of activities and as many as $74.38 \%$ agreed the materials contained a lot of drill exercises such as grammar patterns. These data suggest that though the teacher gave the students some time to speak, her class always organized according to teaching materials which contain a lot of drill exercises, so the teaching method was restricted, and grammar translation method was used frequently.

Table5.1

\begin{tabular}{|l|l|l|l|l|l|}
\hline \multicolumn{1}{|c|}{ Statements } & \multicolumn{4}{|l|}{ Strongly agree---- strongly disagree (\%) } \\
\hline 4. Lost of time spent to practice oral language. & 5.17 & 32.03 & 31.96 & 29.74 & 0 \\
\hline 5. Materials contain lost of interactive activities. & 17.17 & 55.03 & 17.07 & 9.52 & 0 \\
\hline $\begin{array}{l}\text { 6. Materials contain lot of drill exercises such as grammar } \\
\text { patterns. }\end{array}$ & 20.07 & 54.31 & 12.72 & 11.77 & 1.03 \\
\hline
\end{tabular}




\subsection{Teacher's Inappropriate Questioning Skills and Wait-Time}

For Open University English teachers, having a correct judgment of students' proficiency are very important, and it decides whether they can ask appropriate questions. In classroom activities, the teacher's questioning strategies can affect the students' learning. The teacher should have a clear idea that whether a question will be asked before or after the students experience it. So the teacher's questions should not be too easy or too difficult: if they are too easy, the students will be unwilling to answer them because everyone can get the answers without much thinking; if too difficult, the students do not understand the meaning of the questions or they make efforts to think about them but without getting any result, they will be frustrated. It is not surprised that they do not want to answer the questions.

The teacher should set enough time for the students to think about the question. The time should be of different length according to the extent of difficulty of different questions. Too short wait time is a cause that students keep silent because they do not make out answers.

If the questions are not well designed, it is inevitable for the students to keep silent in the class. Still, wait time should be long enough for the students to think about the questions.

Table5.2

\begin{tabular}{|l|l|l|l|l|l|}
\hline Statements & \multicolumn{4}{|l|}{ Strongly agree--- strongly disagree (\%) } \\
\hline 30. The teachers' questions are too difficult or too easy to me. & 0 & 8.42 & 20.26 & 50.01 & 19.61 \\
\hline 32. Wait time is not long enough. & 4.21 & 21.33 & 30.60 & 36.13 & 7.24 \\
\hline
\end{tabular}

The above two statements are primarily about the teacher's questioning skills and the time he/she sets for students. $8.46 \%$ of the students were in favor of the statement that the teacher's questions were too easy or too difficult, while $59.62 \%$ felt the questions were proper to them; about one fourth of the students thought the wait-time was not long enough for them to consider about the questions, while $43.37 \%$ thought they could figure out the answer during the wait-time the teacher leave them. These data explicitly expresses that part of the questions were not of the same level with their proficiency, and the wait-time was not long enough to most students and this was a reason why they kept silent.

\subsection{Classroom Environment}

Classroom environment affects students' performance directly. In above table, almost all the students held the point that relaxing environment is necessary for speaking English. Active classroom climate can motivate the students to perform better. The relationship between the teacher and students is listed as one reason that makes students remain silent. So creating a relaxing environment and dealing well with teacher-students relationship can be an impetus to elicit students' talking.

Table5.3

\begin{tabular}{|c|l|l|l|l|l|}
\hline Statements & \multicolumn{3}{|l|}{ Strongly agree--- strongly disagree (\%) } \\
\hline 9. Relaxing environment is important for practicing oral English. & 54.21 & 37.18 & 4.31 & 3.29 & 1.01 \\
\hline 28. On bad terms with the teacher, I would rather keep silent. & 0 & 9.52 & 21.33 & 45.79 & 23.35 \\
\hline
\end{tabular}

\section{Conclusion}

Students' silence in classroom is regarded as a negative phenomenon and has received much concern by a lot of researchers.

It can be seen as a failure of the interaction between the students and the teacher. The silence phenomenon occurred more often in the Open University English class because the students' language proficiency is not very high. The present study first made a literature review of students' silence in language class. And then based on the data collected from the three kinds of instrument, the reasons of the Open University students' classroom silence were explored and identified. The reasons are mainly expressed in two aspects, that is, from the students' aspect and the teachers' aspect. From the perspective of students, classroom silence is resulted from students' low English proficiency, passive learning habit, and some affective factors such as motivation, learning anxiety, and their no interest in English learning as well as lack of confidence. From the perspective of the teacher, classroom silence is resulted from the teacher's traditional teaching methods, inappropriate questioning skills and not enough wait time, and the classroom climax. In retrospect these reasons, it is of great significance to 
take some ways to deal with the phenomenon classroom silence so as to improve English learning. In order to improve classroom silence, the students can create their confidence and reduce their learning anxiety through clear purpose of hard working and positive feedback from the teacher. The students should take part in classroom activities actively and cooperate with the students and the teacher.

\section{REFERENCES}

Liu, M (2006). Reticence in Oral English Classrooms: Causes and Consequences. Asian J. Engl. Lang. Teach, 16: 45-66

Liu N, Little wood W (1997). Why do many students appear reluctant to participate in classroom learning discourse? System, 25(31: 371-384).

Tsui, ABM (1996). Reticence and anxiety in second language learning.in K. M. Bailey \& D. Nunan (eds.) Voices from the language classroom. Cambridge: Cambridge University Press, pp. 145-167

Zou M (2004). EFL learners' perceptions of in-class relationships and their voluntary responses. In Y. Gao (ed.), The social psychology of English learning by Chinese college students. Beijing: Foreign Lang. Teach. Res. Press, pp. 149-167

Tsou, W. L. (2005) Improving speaking skills through instruction in oral classroom participation. Language Annals, 38 (1), pp 46-55.

Hu, Y., \& Fell-Eisenkraft, S. (2003). Immigrant Chinese students' use of silence in the language arts classroom: Perceptions, Reflections, and Actions. Teaching and Learning, 17(2), 55-65.

Lee, S. (1996). Unraveling the model minority stereotype: Listening to Asian American youth. NY: Teachers College Press.

Losey, M. K. (1997). Listen to the silences: Mexican American interaction in the composition classroom and the community. Norwood. NJ: Ablex.

Pon, G., Goldstein, T.,\&Schecter,S.R. (2003). Interrupted by silences: The contemporary education of Hong Kong-born Chinese Canadians.In R. Bayley and S.

Tsui, A. M. B. (1996) Reticence and anxiety in second language learning in Nunan, D. (ed) Voices from the language classroom. Cambridge: Cambridge University Press, pp145 - 168.

Wu Zhong-hua. Understanding class silence in China: approach from the perspective of international study [J]. Sino-Us English Teaching. 2008. 4, 35-39.

李景光.大学英语课堂学生沉默行为的原因分析及其相关对策 [J]. 怀化学院学报, 2010,11, 152-153.

杜建军.浅谈中学生英语课堂沉默的原因与对策[[J].学苑漫步, 2011,2: 52

张娟娟. 教师提问--打破高职院校英语课堂沉默的关键点[fJJ.九江职业技术学院学报.2011. 3: 33-35.

\section{AUTHORS' BIOGRAPHY}

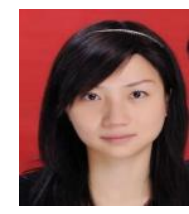

\section{Qi Tang,}

Lecturer from the open University of China, study in English Language teaching.

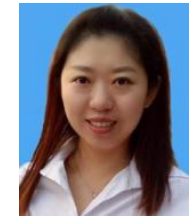

\section{Zhou Shu}

Lecturer from the College of Foreign Language Education in China West Normal University, Study in English teaching and Curriculum. 